\title{
Antifatigue effect of Gracilaria eucheumoides in mice
}

\author{
JIN-TING SHAO ${ }^{1}$, MEI-YAN WANG ${ }^{2}$ and LU-BIN ZHENG ${ }^{3}$ \\ ${ }^{1}$ Physical and Military Training Department, Zhejiang University of Finance and Economics, Hangzhou, Zhejiang 310018; \\ ${ }^{2}$ Sports Center, Zhejiang University of Finance and Economics Dongfang College, Hangzhou, Zhejiang 314408; \\ ${ }^{3}$ Physical Education Department, Shanghai University of Sport, Shanghai 200438, P.R. China
}

Received May 22, 2013; Accepted September 24, 2013

DOI: $10.3892 /$ etm.2013.1346

\begin{abstract}
Gracilaria eucheumoides Linn (Gracilariaceae; G. eucheumoides) is abundant in dietary fiber, which aids the clearance of excess cholesterol from the blood and maintains stable blood glucose levels. The aim of the present study was to investigate the antifatigue effect of $G$. eucheumoides in mice and the physiological and molecular mechanisms underlying this effect. Mice were randomly divided into four groups and three of the groups were administered different doses of G. eucheumoides extract. A loaded swimming test demonstrated that the swimming times of the low-, medium- and high-dose groups were longer than those of the control group. Examinations revealed that the liver and muscle glycogen, lactate dehydrogenase and blood glucose concentration levels of the treatment groups were higher than those of the control group $(\mathrm{P}<0.05)$. However, this was not the case for lactic acid concentration $(\mathrm{P}>0.05)$. Quantitative polymerase chain reaction showed that the gene expression levels of glucose transport protein 4 and AMP-activated protein kinase in the medium-dose group exhibited the largest increases, compared with the other treatment groups, and were 3.0- and 1.8-fold higher than those in the control group, respectively. The results of the present study indicated that $G$. eucheumoides exerts an antifatigue effect on mice.
\end{abstract}

\section{Introduction}

Marine algae, also known as marine vegetables, are naturally rich in polysaccharides, minerals, polyunsaturated fatty acids, vitamins and bioactive molecules. Their nutritional value is markedly higher than that of terrestrial vegetables. The bioactive compounds in marine algae have been reported to possess strong antihypertensive (1-3), antitumor (4,5), anti-inflammatory $(6-8)$, antidiabetic $(9,10)$ and anticoagulant $(11,12)$

Correspondence to: Dr Mei-yan Wang, Sports Center, Zhejiang University of Finance \& Economics Dongfang College, 2 Yangshan Road, Chang'an, Haining, Zhejiang 314408, P.R. China

E-mail: wangmeiyanmmyy@hotmail.com

Key words: seaweed, physical symptoms, glucose transport protein 4, AMP-activated protein kinase properties. In addition, the prebiotic health potential of polysaccharides from seaweeds has been increasingly studied in recent years.

Fatigue, a phenomenon of decreased efficiency following continuous study or work, may be divided into mental and physical fatigue. It mainly manifests as a physical decrease in muscle tone and exercise tolerance due to an accumulation of lactic acid (LC) and other metabolites (13). Fatigue also leads to yawning, as a result of a build-up of carbon dioxide that stimulates the respiratory center. At present, work and life stresses are escalating with the increasing pace of life. Thus, fatigue is common and may significantly affect daily routines. However, a systematic and authoritative hypothesis to explain the induction of fatigue has yet to be suggested. As technology has progressed, a number of scientists have begun to investigate fatigue-associated genes and proteins in order to reveal the mechanisms underlying fatigue and improve therapeutic strategies $(14,15)$.

Gracilaria eucheumoides Linn (Gracilariaceae; G. eucheumoides), a species of seaweed, is a type of natural edible green algae that primarily grows on the southeast coast of China (16). It contains numerous vitamins and microelements, and is abundant in dietary fiber, which aids the clearance of excess cholesterol from the blood and maintains stable blood glucose levels (17). Therefore, G. eucheumoides may have medicinal value and has the potential to be exploited as a functional ingredient in human and animal health applications. Although G. eucheumoides has previously been used in health products in China, to the best of our knowledge its antifatigue effects have not yet been reported. In the present study, the water extract of G. eucheumoides was administered to three groups of mice, and the exhaustive swimming times and relevant physiological indices were measured in order to determine the antifatigue effects of G. eucheumoides. Furthermore, the expression levels of glucose transport protein 4 (GLUT4) and AMP-activated protein kinase (AMPK) were analyzed using quantitative polymerase chain reaction (qPCR) and western blotting. The results demonstrated that $G$. eucheumoides extract may improve the ability to fight fatigue in mice.

\section{Materials and methods}

Preparation of G. eucheumoides extract. The water extract of G. eucheumoides was prepared following a method described previously (18). 
Grouping and treatment of the mice. Healthy male Kunming mice, weighing 10-22 g, were purchased from the Institute of Laboratory Animal Sciences of the Chinese Academy of Medical Sciences (Beijing, China). A total of 40 mice were randomly divided into four groups of ten: Low- $(20 \mathrm{mg} / \mathrm{kg})$, medium- $(40 \mathrm{mg} / \mathrm{kg})$ and high-dose $(80 \mathrm{mg} / \mathrm{kg})$ groups and a normal control group (normal saline). Each mouse was weighed and fed with $0.02 \mathrm{ml} / \mathrm{g} \mathrm{G}$. eucheumoides extract by gavage daily for 30 days. The G. eucheumoides extract was diluted with purified water to the designated concentration. The health status of the mice was observed each day and all the animals were weighed every three days. The quantity of feed was determined in line with the weight of the animals for the 30 days. All mice were freely fed and watered during the experiment. All animal procedures were reviewed and approved by the Shanghai University of Sport Science Research Ethics Committee (chiCTR-TRC-120050028; Shanghai, China).

Loaded swimming test. Thirty minutes subsequent to the final administration of $G$. eucheumoides, a lead sheath, weighing $5 \%$ of the body weight of the mouse, was tied to the root of the tail, prior to the mouse being placed in a water container. The swimming time (time between being placed in the water and sinking underwater for $>10 \mathrm{sec}$ ) was recorded. The water depth was $\geq 30 \mathrm{~cm}$ and the temperature was $25 \pm 1^{\circ} \mathrm{C}$.

Determination of hepatic and muscle glycogen. Thirty minutes subsequent to the final feed, non-loaded mice were placed in a water container and left to swim for $90 \mathrm{~min}$ at a temperature of $25 \pm 1^{\circ} \mathrm{C}$. The mice were then sacrificed by cervical vertebra dislocation, cleaned using normal saline and dried with filter paper. Subsequently, $100 \mathrm{mg}$ liver tissue and $500 \mathrm{mg}$ quadriceps femoris tissue were weighed and diluted to $10 \%$ homogenate with normal saline. Following centrifugation at $800-1,800 \mathrm{x} \mathrm{g}$ for $10 \mathrm{~min}$, the supernatant was used to determine the quantity of glycogen using the Anthrone colorimetric method.

Measurement of LC, lactate dehydrogenase ( $\mathrm{LDH}$ ) and blood glucose concentrations. Thirty minutes subsequent to the final feed, non-loaded mice were left to swim for $90 \mathrm{~min}$ at a temperature of $25 \pm 1^{\circ} \mathrm{C}$. Subsequently, venous blood was collected from the tail and the LC, LDH and blood glucose concentrations were determined using the LC kit (Cat. No. A019-1), LDH kit (Cat. No.A020) and glucose kit (Cat. No.F006) from Nanjing Jiancheng BioEngineering Institute (Nanjing, China), in accordance with the manufacturer's instructions.

qPCR. Thirty minutes subsequent to the final feed, non-loaded mice were left to swim for $90 \mathrm{~min}$ at a temperature of $25 \pm 1^{\circ} \mathrm{C}$. Subsequently, the mice were sacrificed by cervical vertebra dislocation and cleaned using normal saline. Following drying with filter paper, 50-100 mg quadriceps femoris tissue was weighed and RNA was isolated using TRIzol reagent ${ }^{\circledR}$ (Invitrogen Life Technologies, Carlsbad, CA, USA) according to the manufacturer's instructions. The specific primer pairs designed for the amplification of GLUT4 and AMPK, and the reference gene of $18 \mathrm{~s}$ RNA, are exhibited in Table I. All qPCR reactions were performed using a CFX-96 Real-Time
Table I. Primer sequences of target and reference genes used for quantitative polymerase chain reaction analyses.

\begin{tabular}{lll}
\hline Primer & Direction & Sequence (5'-3') \\
\hline GLUT4 & Forward & 5'-TCGTGGCCATATTTGGCTTTGTGG-3' \\
& Reverse & 5'-TAAGGACCCATAGCATCCGCAACA-3' \\
AMPK & Forward & 5'-TGACCGGACATAAAGTGGCTGTGA-3' \\
& Reverse & 5'-TGATGATGTGAGGGTGCCTGAACA-3' \\
18sRNA & Forward & 5'-CCTGGATACCGCAGCTAGGA-3' \\
& Reverse & 5'-GCGGCGCAATACGAATGCCCC-3' \\
\end{tabular}

GLUT4, glucose transport protein 4; AMPK, AMP-activated protein kinase.

PCR detection System (Bio-Rad, Hercules, CA, USA). Each 25- $\mu 1$ reaction consisted of $12.5 \mu \mathrm{l} \mathrm{SYBR}$ Green I, $5 \mu \mathrm{l}$ cDNA, $2.5 \mu \mathrm{l}$ forward and reverse primer, and $2.5 \mu \mathrm{l}$ sterile water. The conditions for PCR were 40 cycles of: $95^{\circ} \mathrm{C}, 3 \mathrm{sec}$; $60^{\circ} \mathrm{C}, 5 \mathrm{sec}$; and $72^{\circ} \mathrm{C}, 30 \mathrm{sec}$. Following PCR, a melting curve analysis was performed in order to demonstrate the specificity of the PCR products. Each reaction was run in triplicate and the results were analyzed using SPSS 15.0 statistical software (SPSS, Inc., Chicago, IL, USA).

Protein extraction and western blot analysis. Thirty minutes subsequent to the final feed, non-loaded mice were left to swim for $90 \mathrm{~min}$ at a temperature of $25 \pm 1^{\circ} \mathrm{C}$. Subsequently, the mice were sacrificed by cervical vertebra dislocation and cleaned using physiological saline. Following drying with filter paper, $40 \mathrm{mg}$ quadriceps femoris tissue was weighed and lysed in a lysis buffer consisting of $50 \mathrm{mM}$ Tris- $\mathrm{HCl}$ (pH 7.4-8.0), $150 \mathrm{mM} \mathrm{NaCl}, 5$ mM EDTA, 1\% Triton ${ }^{\mathrm{TM}}$ $\mathrm{X}-100$, and $1 \mathrm{mM}$ PMSF. Protein concentrations were determined using a bicinchoninic acid protein assay (Pierce Chemical Co., Rockford, IL, USA) using bovine serum albumin as a standard. Protein samples of a total of $20 \mu \mathrm{g}$ were separated using sodium dodecyl sulfate-polyacrylamide gel electrophoresis (SDS-PAGE) technology and were transferred to polyvinylidene difluoride (PVDF) membranes. The plates were blocked with $5 \%(\mathrm{w} / \mathrm{v})$ nonfat milk powder for $2 \mathrm{~h}$ at room temperature and immunoblotted with primary antibodies. Following one night at $4{ }^{\circ} \mathrm{C}$, the secondary antibodies were added and the antigen-antibody complex was detected using an enhanced chemiluminescence (ECL) kit (Amersham Pharmacia Biotech, Piscataway, NJ, USA) in accordance with the manufacturer's instructions. $\beta$-actin was treated as a control. The primary antibodies and secondary antibodies used were as follows: goat anti-GLUT4 (Santa Cruz Biotechnology, Inc., Santa Cruz, CA, USA; sc-1608), goat anti-AMPK (Santa Cruz Biotechnology, Inc.; sc-19126) and donkey anti-goat IgG-HRP (Santa Cruz Biotechnology, Inc.; sc-2020).

Statistical analysis. All statistical procedures were performed using SPSS version 15.0 (SPSS, Inc.). Data are expressed as the mean \pm standard deviation (SD). Differences between groups were analyzed using one-way analysis of covariance. $\mathrm{P}<0.05$ 
Table II. Effect of G. eucheumoides extract on the loaded swimming time of mice.

\begin{tabular}{lcccc}
\hline Group & $\begin{array}{c}\text { Dose } \\
(\mathrm{mg} / \mathrm{kg})\end{array}$ & $\begin{array}{c}\text { Number of } \\
\text { mice }\end{array}$ & $\begin{array}{c}\text { Loaded swimming } \\
\text { time }(\mathrm{sec})\end{array}$ & $\begin{array}{c}\text { Increment rate of loaded } \\
\text { swimming time }(\%)\end{array}$ \\
\hline Control & 0 & 10 & $31.3 \pm 0.2$ & - \\
Low-dose & 20 & 10 & $38.7 \pm 0.4$ & $19.1^{\mathrm{a}}$ \\
Medium-dose & 40 & 10 & $41.3 \pm 0.5$ & $32.0^{\mathrm{b}}$ \\
High-dose & 80 & 10 & $36.4 \pm 0.2$ & $16.3^{\mathrm{a}}$ \\
\hline
\end{tabular}

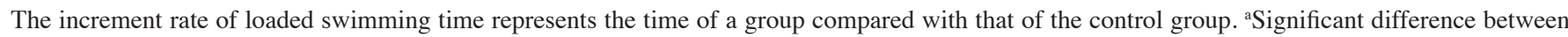
the treatment and control groups $(\mathrm{P}<0.05)$; ${ }^{b}$ highly significant difference between the treatment and control groups $(\mathrm{P}<0.01)$.

Table III. Analysis of liver and muscle glycogen, LC, LDH and blood glucose concentration in mice.

\begin{tabular}{|c|c|c|c|c|c|}
\hline Group & $\begin{array}{l}\text { Liver glycogen } \\
\quad(\mathrm{g} / 100 \mathrm{~g})\end{array}$ & $\begin{array}{l}\text { Muscle glycogen } \\
(\mathrm{g} / 100 \mathrm{~g})\end{array}$ & $\begin{array}{l}\mathrm{LDH} \\
(\mathrm{U} / \mathrm{l})\end{array}$ & $\begin{array}{l}\text { LC concentration } \\
(\mathrm{mM})\end{array}$ & $\begin{array}{c}\text { Blood glucose } \\
\text { concentration }(\mathrm{g} / \mathrm{l})\end{array}$ \\
\hline Control & $1.25 \pm 0.02$ & $0.55 \pm 0.00$ & $55.3 \pm 0.30$ & $18.6 \pm 0.10$ & $0.83 \pm 0.10$ \\
\hline Low-dose & $1.43 \pm 0.04^{\mathrm{a}}$ & $0.78 \pm 0.01^{\mathrm{a}}$ & $76.9 \pm 0.40^{\mathrm{a}}$ & $15.4 \pm 0.06^{\mathrm{a}}$ & $1.10 \pm 0.06^{\mathrm{a}}$ \\
\hline Medium-dose & $1.86 \pm 0.00^{\mathrm{b}}$ & $1.12 \pm 0.11^{\mathrm{b}}$ & $90.3 \pm 0.50^{\mathrm{b}}$ & $13.8 \pm 0.10^{\mathrm{b}}$ & $1.38 \pm 0.10^{\mathrm{b}}$ \\
\hline High-dose & $1.64 \pm 0.03^{\mathrm{a}}$ & $0.82 \pm 0.09^{\mathrm{a}}$ & $94.2 \pm 0.20^{\mathrm{b}}$ & $11.3 \pm 0.10^{\mathrm{b}}$ & $1.13 \pm 0.10^{\mathrm{b}}$ \\
\hline
\end{tabular}

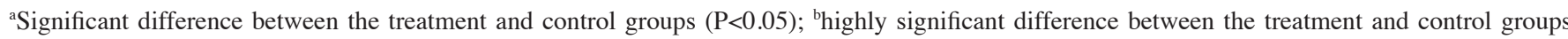
$(\mathrm{P}<0.01)$. LC, lactic acid; LDH, lactate dehydrogenase.

was considered to indicate a statistically significant difference and $\mathrm{P}<0.01$ was considered highly significant.

\section{Results}

Effect of $G$. eucheumoides extract on the loaded swimming time of mice. The mice in the three G. eucheumoides extract treatment groups were subjected to the loaded swimming test. The results of the test are exhibited in Table II.

The loaded swimming times of the low-, medium- and high-dose groups were greater than those of the control group. Among the three treatment groups, the loaded swimming time of the medium-dose group was the longest $(41.3 \pm 0.5 \mathrm{~min})$. The increment rate of the loaded swimming time for the medium-dose group was $32 \%$, which was significantly different from the control group. Furthermore, the increment rates of the low- and high-dose groups showed significant increases of 19.1 and $16.3 \%$, respectively, compared with the control group. These results indicated that G. eucheumoides extract may extend the loaded swimming time of mice.

Effect of $G$. eucheumoides extract on liver and muscle glycogen, LC, LDH and blood glucose concentrations of mice. In order to investigate the mechanism underlying the antifatigue effect of G. eucheumoides extract, the liver and muscle glycogen, LC, LDH and blood glucose concentrations of mice were measured following the non-loaded swimming test (Table III).

It was revealed that the relevant physiological indices of the treatment groups were significantly increased compared with those of the control group $(\mathrm{P}<0.05)$, with the exception of

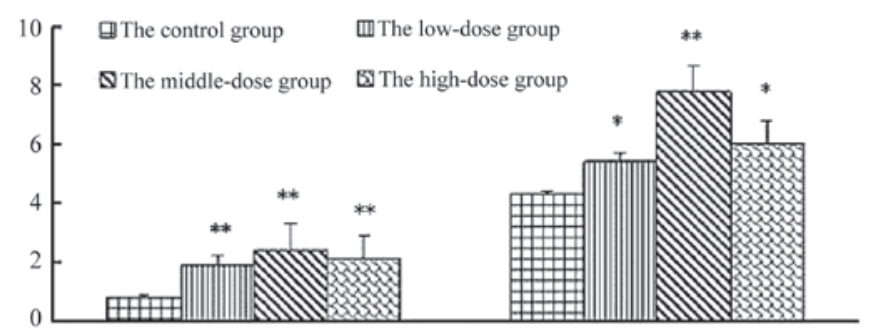

GLUT4

AMPK

Figure 1. Expression of GLUT4 and AMPK genes in mice fed with G. eucheumoides extract of different concentrations." Difference between the treatment and control groups was significant $(\mathrm{P}<0.05) ;{ }^{* *}$ difference between the treatment and control groups was highly significant $(\mathrm{P}<0.01)$. GLUT4, glucose transport protein 4; AMPK, AMP-activated protein kinase.

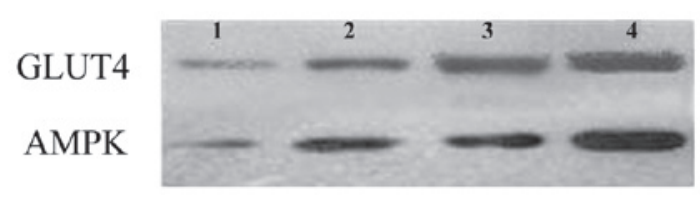

Figure 2. GLUT4 and AMPK protein expression in mice fed with G. eucheumoides extract of different concentrations. Lane 1, control group; 2, low-dose group; 3, medium-dose group; 4, high-dose group. GLUT4, glucose transport protein 4; AMPK, AMP-activated protein kinase.

the LC concentration. In the treatment groups, liver glycogen and muscle glycogen and blood glucose concentrations initially increased and then decreased as the extract dose was increased. LDH concentration increased with an increasing dose, while LC concentration decreased. These results 
indicated that $G$. eucheumoides extract significantly alters the liver and muscle glycogen, LDH, LC and blood glucose concentrations of mice.

Effect of $G$. eucheumoides extract on the gene expression levels of GLUT4 and AMPK. To investigate the molecular role of G. eucheumoides extract in mice, the expression levels of GLUT4 and AMPK were determined using qPCR (Fig. 1). Compared with the control group, the expression levels of GLUT4 and AMPK were significantly increased in the treatment groups. The expression levels of the two genes were increased to the greatest extent in the medium-dose group and were 3.0- and 1.8-fold higher than those in the control group, for GLUT4 and AMPK respectively. These results demonstrated that $G$. eucheumoides extract may regulate the expression levels of GLUT4 and AMPK in the muscle of mice.

Effect of $G$. eucheumoides extract on protein expression levels of GLUT4 and AMPK. The protein expression levels of GLUT4 and AMPK were further characterized by western blotting (Fig. 2). The results showed that protein expression levels of GLUT4 and AMPK increased gradually with an increasing extract dose. Although the expression levels of these proteins reached their peaks in the high-dose group, the increasing trends were different between the proteins. GLUT4 was significantly increased from the low-dose group to the medium-dose group, while AMPK was significantly increased from the medium-dose group to the high-dose group. In combination, these results suggested that $G$. eucheumoides extract enhanced the protein expression of GLUT4 and AMPK in mice.

\section{Discussion}

Fatigue is a normal physiological or psychological phenomenon, usually associated with physical and/or mental weakness, varying from a general state of lethargy to a specific work-induced burning sensation within the muscles. Prolonged and high intensity exercise leads to an inadequate oxygen supply at the physiological level. In order to maintain physical functioning, the body primarily performs glucose metabolism, which is dependent on the glycolytic pathway and results in significant consumption of glycogen and accumulation of fatigue-inducing metabolites, including LC (13).

The bioactive compounds derived from seaweed may be classified into two types: Indigestible intercellular viscous polysaccharides, including alginic acid, fucoidan, rhodophyte agar and carrageenan $(19,20)$, and digestible compounds with low molecular weights, including halide, terpenoid, bromophenol compound, algae tannin and laminin $(5,21,22)$. The latter type are capable of being absorbed by the human body and regulate metabolism directly and indirectly. G. eucheumoides contains several types of vitamins and microelements, and is abundant in dietary fiber. The human consumption of dietary fiber has been correlated with a number of health-promoting effects, including growth promotion, the protection of beneficial intestinal flora and the reduction of the overall glycemic response. Thus, at present G. eucheumoides is is a topic of interest.
In the present study, the loaded swimming times of mice fed with G. eucheumoides extract were significantly increased compared with those of the control group, indicating that the extract may enhance tolerance to fatigue in mice. Analysis of physical indices demonstrated that the liver and muscle glycogen, LDH and blood glucose concentrations of mice in the treatment groups were significantly increased compared with those in the control group. Furthermore, the LC concentrations of the treatment groups were significantly decreased compared with those of the control group. Glycogen serves as a form of energy storage in animals and is stored primarily in the cells of the liver and the muscles (23). Energy is supplied via hepatic glycogen degradation when blood glucose is depleted. The results of this study suggested that G. eucheumoides may improve the energy efficiency of mice.

During high intensity exercises, blood glucose is metabolized and oxidized to pyruvate, and LC is produced from the pyruvate at a greater speed than tissues are capable of removing it. Therefore, the LC concentration begins to rise $(24,25)$. The LC concentration of mammalian blood is $1-2 \mathrm{mM}$ when sitting still and may increase to $20 \mathrm{mM}$ during strenuous exercise. During the present experiments, the LC concentration decreased to $11.3 \mathrm{mM}$ in the high-dose group and the concentration of $\mathrm{LDH}$ increased following exercise. LDH catalyzes the oxidation of LC, forming pyruvate. Therefore, mice fed with G. eucheumoides extract experienced a reduction in blood LC concentration as a result of increased LDH concentration.

In order to investigate the molecular mechanisms underlying the antifatigue effect of $G$. eucheumoides, the mRNA and protein expression of AMPK and GLUT4 were examined using qPCR and western blotting, respectively. AMPK has a central role in the control of metabolism in cells, and operates an alternative pathway of energy synthesis when cellular energy is low $(26,27)$. GLUT4 transports glucose in adipose tissue and muscle, and is important in energy metabolism and the antifatigue process (28). In this study, mRNA and protein expression levels of AMPK and GLUT4 were significantly increased in the treatment groups compared with those of the control group. However, the expression levels were increased in different manners. The mRNA and protein levels of GLUT4 increased to their highest levels in the high-dose group. The mRNA expression of AMPK also increased to its highest level in the medium-dose group; however, the protein expression level of AMPK increased to its highest level in the high-dose group. It is possible that $G$. eucheumoides may not only promote the levels of gene and protein expression of AMPK and GLUT4, but also initiate other methods of energy synthesis in order to meet energy requirements and avoid severe hypoglycemia during vigorous exercise. Furthermore, the enhanced expression of GLUT4 protein may improve glucose transport rates, thus increasing its utilization.

In conclusion, the antifatigue effect of G. eucheumoides was analyzed and the physiological and molecular mechanisms underlying this effect were investigated. The results demonstrated that G. eucheumoides exerts marked antifatigue effects, which may be achieved by regulating antifatigue-associated genes and increasing LDH concentration. Further studies are required to investigate the mechanims underlying these properties of G. eucheumoides. 


\section{References}

1. Bocanegra A, Bastida S, Benedí J, Nus M, Sánchez-Montero JM and Sánchez-MunizFJ:Effect of seaweed and cholesterol-enriched diets on postprandial lipoproteinaemia in rats. Br J Nutr 102: 1728-1739, 2009.

2. Wada K, Nakamura K, Tamai Y, et al: Seaweed intake and blood pressure levels in healthy pre-school Japanese children. Nutr J 10: 83, 2011.

3. Blokhuis TJ and Arts JJ: Bioactive and osteoinductive bone graft substitutes: definitions, facts and myths. Injury 42 (Suppl 2): S26-S29, 2011

4. Ahmed HH, Hegazi MM, Abd-Alla HI, Eskander EF and Ellithey MS: Antitumour and antioxidant activity of some Red Sea seaweeds in Ehrlich ascites carcinoma in vivo. Z Naturforsch C 66: 367-376, 2011.

5. Wijesinghe WA and Jeon YJ: Exploiting biological activities of brown seaweed Ecklonia cava for potential industrial applications: a review. Int J Food Sci Nutr 63: 225-235, 2012.

6. Coura CO, de Araújo IW, Vanderlei ES, et al: Antinociceptive and anti-inflammatory activities of sulphated polysaccharides from the red seaweed Gracilaria cornea. Basic Clin Pharmacol Toxicol 110: 335-341, 2012.

7. Siqueira RC, da Silva MS, de Alencar DB, et al: In vivo anti-inflammatory effect of a sulfated polysaccharide isolated from the marine brown algae Lobophora variegata. Pharm Biol 49: 167-174, 2011.

8. Yuvaraj N, Kanmani P, Satishkumar R, Paari A, Pattukumar V and Arul V: Seagrass as a potential source of natural antioxidant and anti-inflammatory agents. Pharm Biol 50: 458-467, 2012.

9. Xu HL, Kitajima C, Ito H, et al: Antidiabetic effect of polyphenols from brown alga Ecklonia kurome in genetically diabetic KK-A(y) mice. Pharm Biol 50: 393-400, 2012.

10. Lee YS, Shin KH, Kim BK and Lee S: Anti-diabetic activities of fucosterol from Pelvetia siliquosa. Arch Pharm Res 27: 1120-1122, 2004.

11. Albuquerque IR, Queiroz KC, Alves LG, Santos EA, Leite EL and Rocha HA: Heterofucans from Dictyota menstrualis have anticoagulant activity. Braz J Med Biol Res 37: 167-171, 2004.

12. Silva TM, Alves LG, de Queiroz KC, et al: Partial characterization and anticoagulant activity of a heterofucan from the brown seaweed Padina gymnospora. Braz J Med Biol Res 38: 523-533, 2005.

13. Bogdanis GC: Effects of physical activity and inactivity on muscle fatigu. Front Physiol 3: 142, 2012.
14. Saiki T, Kawai T, Morita K, et al: Identification of marker genes for differential diagnosis of chronic fatigue syndrome. Mol Med 14: 599-607, 2008.

15. Finsterer J: Biomarkers of peripheral muscle fatigue during exercise. BMC Musculoskelet Disord 13: 218, 2012.

16. Takano R, Hayashi K and Hara S: Highly methylated agars with a high gel-melting point from the red seaweed, Gracilaria eucheumoides. Phytochemistry 40: 487-490, 1995.

17. Krishnaiah D, Sarbatly R, Prasad DMR and Bono A: Mineral content of some seaweeds from Sabah's south China sea. Asian J Sci Res 1: 166-170, 2008.

18. Zhang X, Li H, Wu G, Ban S and Park H: Extraction of Eupatorium odoratum and its inhibition on toxic cyanobacteria. J Hainan Norm Uni (Nat Sci) 23: 427-432, 2010 (In Chinese).

19. Jiménez-Escrig A, Gómez-Ordóñez E and Rupérez P: Seaweed as a source of novel nutraceuticals: sulfated polysaccharides and peptides. Adv Food Nutr Res 64: 325-337, 2011.

20. Vera J, Castro J, Gonzalez A and Moenne A: Seaweed polysaccharides and derived oligosaccharides stimulate defense responses and protection against pathogens in plants. Mar Drugs 9: 2514-2525, 2011.

21. Lewis AS: Organic versus inorganic arsenic in herbal kelp supplements. Environ Health Perspect 115: A575, 2007.

22. Sun XW, Weng HX and Qin YC: Release of bioactive active iodine in kelp. J Environ Sci (China) 17: 241-244, 2005.

23. Greenberg CC, Jurczak MJ, Danos AM and Brady MJ: Glycogen branches out: new perspectives on the role of glycogen metabolism in the integration of metabolic pathways. Am J Physiol Endocrinol Metab 291: E1-E8, 2006.

24. Brook GA, Dubouchard H, Brown M, Sicurello JP and Butz CE: Role of mitochondrial lactate dehydrogenase and lactate oxidation in the intracellular lactate shuttle. Proc Natl Acad Sci USA 96: 1129-1134, 1999.

25. Scott CB: Contribution of anaerobic energy expenditure to whole body thermogenesis. Nutr Metab (Lond) 2: 14, 2005.

26. Heidrich F, Schotola H, Popov AF, et al: AMPK - activated protein kinase and its role in energy metabolism of the heart. Curr Cardiol Rev 6: 337-342, 2010.

27. Oakhill JS, Steel R, Chen ZP, et al:AMPK is a direct adenylate charge-regulated protein kinase. Science 332: 1433-1435, 2011.

28. Song H, Guang Y, Zhang L, Li K and Dong C. SPARC interacts with AMPK and regulates GLUT4 expression. Biochem Biophys Res Commun 396: 961-966, 2010. 